\title{
Mechanisms contributing to the induction and storage of Pavlovian fear memories in the lateral amygdala
}

\author{
Dongbeom Kim, ${ }^{1}$ Denis Paré, ${ }^{2}$ and Satish S. Nair ${ }^{1,3}$ \\ ${ }^{1}$ Department of Electrical and Computer Engineering, University of Missouri, Columbia, Missouri 65211, USA; ${ }^{2}$ Center for Molecular \\ and Behavioral Neuroscience, Rutgers, The State University of New Jersey, Newark, New Jersey 07102, USA
}

\begin{abstract}
The relative contributions of plasticity in the amygdala vs. its afferent pathways to conditioned fear remain controversial. Some believe that thalamic and cortical neurons transmitting information about the conditioned stimulus (CS) to the lateral amygdala (LA) serve a relay function. Others maintain that thalamic and/or cortical plasticity is critically involved in fear conditioning. To address this question, we developed a large-scale biophysical model of the LA that could reproduce earlier findings regarding the cellular correlates of fear conditioning in LA. We then conducted model experiments that examined whether fear memories depend on (1) training-induced increases in the responsiveness of thalamic and cortical neurons projecting to LA, (2) plasticity at the synapses they form in LA, and/or (3) plasticity at synapses between LA neurons. These tests revealed that training-induced increases in the responsiveness of afferent neurons are required for fear memory formation. However, once the memory has been formed, this factor is no longer required because the efficacy of the synapses that thalamic and cortical neurons form with LA cells has augmented enough to maintain the memory. In contrast, our model experiments suggest that plasticity at synapses between LA neurons plays a minor role in maintaining the fear memory.
\end{abstract}

[Supplemental material is available for this article.]

The ability to associate fear responses to new stimuli or circumstances on the basis of experience is necessary for survival. The experimental paradigm typically used to study this process is Pavlovian fear conditioning, where an initially neutral stimulus (conditioned stimulus [CS]) acquires the ability to elicit conditioned fear responses after pairing with a noxious unconditioned stimulus (US). Although there is evidence that fear conditioning induces widespread synaptic plasticity in the brain, including at thalamic and cortical levels (Letzkus et al. 2011; Weinberger 2011), there are also data indicating that the dorsal portion of the lateral amygdala (LAd) is a critical site of plasticity for the storage of CS-US associations (LeDoux 2000; for review, see Pape and Paré 2010).

For instance, unit recording studies have revealed that auditory fear conditioning increases the CS responsiveness of LAd neurons (Quirk et al. 1995; Collins and Paré 2000; Repa et al. 2001; Goosens et al. 2003). In the most dorsal part of LAd (LAdd), neurons display increases in CS responsiveness that last for only a few trials ("transient cells"), whereas in more ventrally located LAd (LAdv) neurons ("long-term plastic cells"), CS responses are persistently increased, even resisting extinction training (Repa et al. 2001). This has led to the proposal that the two cell types are involved in the initiation of learning vs. long-term storage of the fear memory, respectively (Repa et al. 2001). However, the mechanisms contributing to the formation of these two response types remain unknown.

Similarly, although it is well established that fear conditioning increases the CS responsiveness of thalamic and cortical neurons projecting to LA (for review, see Weinberger 2011), the contributions of CS afferent pathways to conditioned fear memories remain controversial. In particular, it has been impossible to

\footnotetext{
${ }^{3}$ Corresponding author

E-mail nairs@missouri.edu

Article is online at http://www.learnmem.org/cgi/doi/10.1101/lm.030262.113.
}

determine the relative importance of plasticity within LA vs. CS inputs to LA. To address these questions, we developed a biologically realistic computational model of LAd that could reproduce the transient and long-term plastic LAd cells previously observed by Repa et al. (2001) and then conducted a series of experimentally impossible manipulations to probe the contributions of plasticity in CS afferent pathways vs. within LAd to conditioned fear.

\section{Results}

We have developed a biophysically realistic model of LAd to investigate the mechanisms underlying the different temporal patterns of increased tone responsiveness displayed by neurons in the dorsal and ventral parts of LAd during fear conditioning (Repa et al. 2001). The simulated LAd network included conductance-based models of 800 principal cells and 200 interneurons that reproduced the electroresponsive properties of these cell types, as observed experimentally (Fig. 1; for review, see Sah et al. 2003), and neuromodulatory inputs from brainstem dopaminergic and noradrenergic neurons (Johnson et al. 2011). In addition, based on previous in vitro experiments (Samson and Paré 2006), the model network integrated spatially differentiated patterns of excitatory and inhibitory connections within LA (Fig. 2). Last, all the glutamatergic synapses in the model could undergo both short-term and long-term activity-dependent plasticity, except for those delivering shock or background inputs (see Materials and Methods).

The training paradigm we used is shown in Figure 2C. In Figures 3-7, all data points represent a block of four trials, except for the first, which is the average of the final six habituation trials, as in Repa et al. (2001). All reported values are averages \pm SEM expressed as percent change from control and tone responses (see representative examples in Supplemental Fig. S1) computed as spikes per tone within 200 msec of tone onset. 


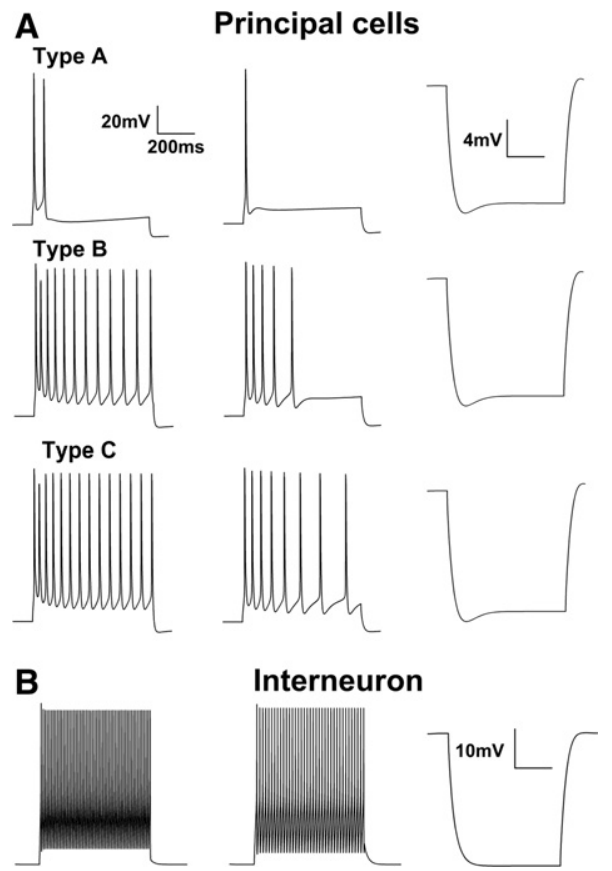

Figure 1. Electroresponsive properties of model LA neurons. Voltage responses of model cells to intracellular current injection. $(A)$ The responses of the three types of principal cells (types A, B, and C) to current injections (left, $400 \mathrm{pA}$; middle, $300 \mathrm{pA}$; right, $-100 \mathrm{pA}$; duration $600 \mathrm{msec}$ ) are similar to those reported in Faber et al. (2001). (B) Voltage responses of the interneuron model to 200-msec current injections of the same magnitude as in $A$.

\section{Impact of fear conditioning on the tone responsiveness of LAd neurons}

There is a long-standing controversy in the field regarding the relative contributions of plasticity in the amygdala vs. CS afferent pathways to conditioned fear (Paré 2002). One view posits that thalamic and cortical neurons transmitting CS information to LA merely serve as sensory relays. Another stipulates that thalamic and/or cortical plasticity is critical for fear conditioning (for review, see Weinberger 2011). Thus, we first examined whether our model could reproduce the findings of Repa et al. (2001) when the CS responsiveness of thalamic and cortical neurons relaying tone information to LAd remained unchanged at $20 \mathrm{~Hz}$ (habituation level) through conditioning.

In these conditions (Fig. 3, empty triangles), the model could not reproduce the findings of Repa et al. (2001) (Fig. 3, solid circles). Indeed, whereas Repa et al. (2001) observed that $24 \%$ of LAd cells developed increased tone responses as a result of fear conditioning, only $9 \%$ (or 75 of 800 ) did so in the model experiment with thalamic and cortical tone-evoked firing rates unchanged at $20 \mathrm{~Hz}$ through conditioning. Moreover, when we considered cells that showed significant increases in tone responsiveness, as identified using the criterion of Repa et al. (2001), their average tone responses were much lower $(<50 \%)$ than seen experimentally (Fig. 3). Various modifications to the model, including the distribution or strength of thalamic and cortical inputs, the $\mathrm{Ca}^{2+}$-dependence of synaptic plasticity in LAd neurons, as well as the intrinsic connectivity within LAd, failed to alter this basic conclusion (Supplemental Fig. S2).

Since many studies reported that fear conditioning does increase the tone responsiveness of CS afferent neurons and that such changes play a critical role in the formation of conditioned fear memories (Quirk et al. 1997; Hennevin and Maho 2005;
Letzkus et al. 2011; Weinberger 2011), we next ran the same "behavioral" protocol but increased the firing rate of thalamic inputs during the CS from $20 \mathrm{~Hz}$ to $40 \mathrm{~Hz}$ after one conditioning trial, and after six trials for cortical inputs, in keeping with prior experimental observations (Quirk et al. 1997). With this modification (Fig. 3, gray squares), the model successfully replicated the impact of fear conditioning and extinction training on the CS responsiveness of principal LAd cells, as described in Repa et al. (2001).

To assess the model's ability to reproduce these earlier results (Fig. 4A1,A2, black curves), we relied on the criteria used by Repa et al. (2001) to analyze the behavior of LAd cells. That is, as a first step, model neurons were classified as plastic if their CS-elicited firing during any of the four trial conditioning blocks was higher than the habituation level using a $t$-test with a significance threshold of $P<0.05$. In a second step, a "persistence" value was calculated for each plastic cell by dividing the increase in CS responses during late conditioning (final eight trials) by that seen during early conditioning (first eight trials), both relative to habituation. As in Repa et al. (2001), plastic cells with persistence values of $<0.75$ were classified as "transiently plastic" (TP) cells (Fig. $4 \mathrm{~A} 1$ ), and those with persistence values $>0.75$ were classified as "long-term plastic" (LP) cells (Fig. 4A2).

In the model, $24.7 \%(198 / 800)$ of principal LAd cells were plastic cells (LP and TP cells), which is similar to experimental observations (24/100; Repa et al. 2001) with 12\% (96/800) being TP cells and $12.7 \%(102 / 800)$ being LP cells, again similar to experimental values (12\% for each type; Repa et al. 2001). Moreover, whereas TP cells were largely found in LAdd (75 of 96) (Fig. 5), model LP cells were more widely distributed in LAd (47 and 55 of 102 in LAdd and LAdv, respectively) (Fig. 5), as again seen experimentally ( 5 and 7 of 12; Fig. 8 of Repa et al. 2001), and so providing validation for the model. Last, model TP and LP neurons reproduced the behavior of the corresponding cell types during extinction, as seen experimentally (Fig. 4A). That is, the tone responses of TP cells were at habituation levels except during the first block of extinction $(P<0.001)$ (Fig. 4A1). In contrast, LP cells retained higher levels of tone responsiveness throughout extinction $(P<0.001)$ (Fig. 4A2).

Although the above suggests that conditioning-induced increases in the CS responsiveness of thalamic and cortical neurons are required for the emergence of LP and TP cells (Figs. 3, 4B), it remains unclear whether the altered CS responsiveness of LAd neurons, once induced, remains dependent on an augmented signaling of the CS by thalamic and cortical neurons. To address this question, we ran the same simulation as above with the exception that the firing rates of thalamic and cortical CS inputs during the CS were returned to habituation levels during the recall test. Unexpectedly, this manipulation did not alter the average tone responses of TP cells (Fig. 4C1, squares) and LP cells (Fig. 4C2, squares), only causing a small and statistically insignificant decrease $(10 \%, P=0.33)$ in their tone responses. Overall, the above simulations indicate that increases in the CS responsiveness of thalamic and cortical neurons projecting to LAd are required for the development of the LAd plasticity but that, once induced, it is plasticity in LAd that mainly contributes to maintain the increased tone responsiveness of TP and LP cells.

\section{Role of input connectivity in the formation of TP and LP cells}

To determine whether the emergence of TP and LP cells was dependent on the particular connections they formed, we compared their intrinsic and extrinsic connectivity. Since TP and LP cells were more prevalent in LAdd vs. LAdv, respectively (Fig. 5; TP, red; LP, blue), we first compared the inputs to principal cells in 


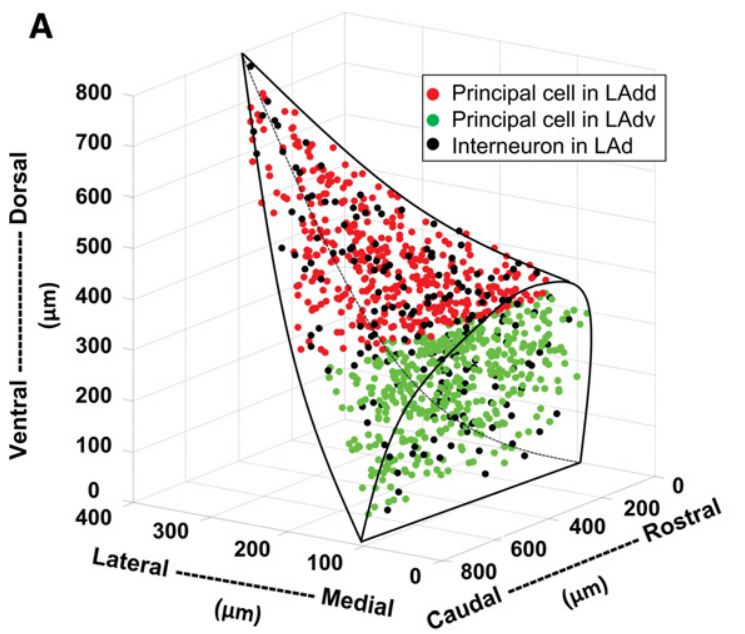

B Coronal plane connectivity

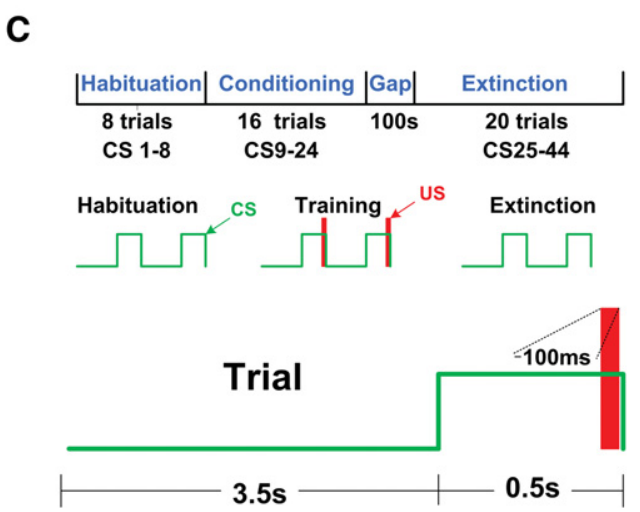

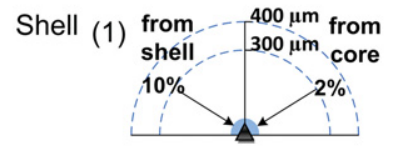

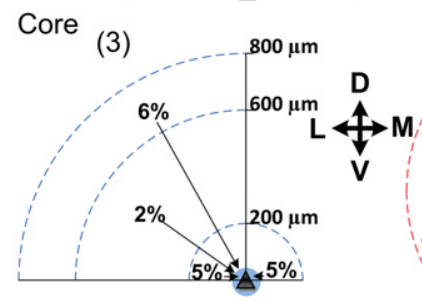

(2)
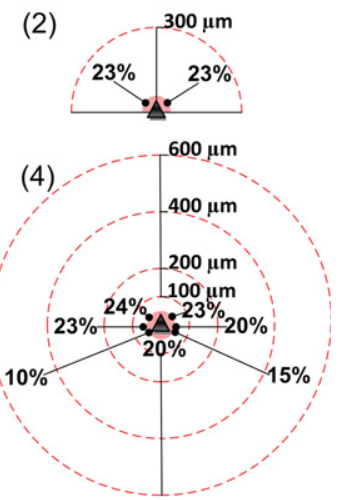

Horizontal plane connectivity

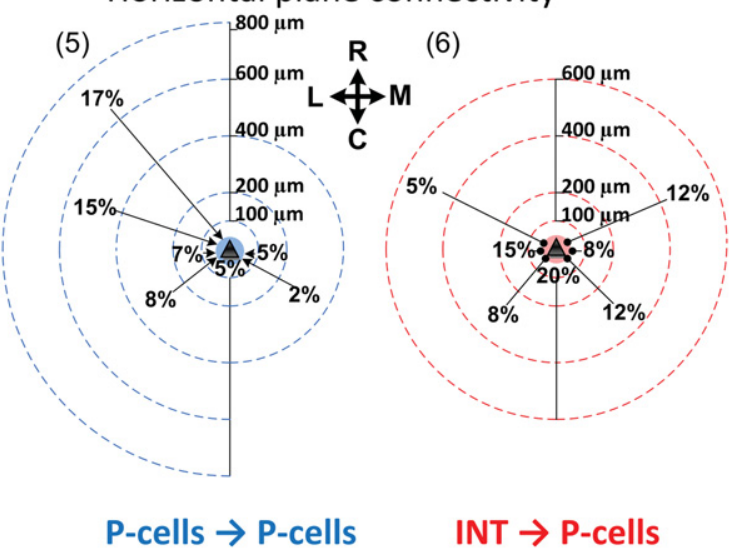

Figure 2. Spatial structure, intrinsic connectivity, and fear conditioning protocol for the LAd network model. (A) The model consists of 800 principal cells (red and green dots, 400 each, represent principal cells in LAdd and LAdv, respectively) and 200 interneurons (black dots). The principal cells in the model were populated randomly in the horn-shaped tridimensional structure with dimensions of $800 \mu \mathrm{m}$ in the rostral-caudal, $800 \mu \mathrm{m}$ in the ventraldorsal, and $400 \mu \mathrm{m}$ in the medial-lateral directions. (B) Intrinsic connectivity of the model in the coronal and horizontal planes: glutamatergic connections to principal cells (blue) and GABAergic connections to principal cells (red). Excitatory connections to principal cells were different in shell and core regions of LAd. (1) Shell neurons in the dorsal region excited principal cells in the ventral region (e.g., for cells separated by $300-400 \mu \mathrm{m}$, the connectivity was 10\%). (2) Principal cells in the ventral shell region are inhibited by interneurons in the dorsal region (for distances between $50 \mu \mathrm{m}$ and $300 \mu \mathrm{m}$, the connectivity was 23\%). (3) Within the core region, cells in the dorsolateral region excited principal cells in the ventromedial region (e.g., cells within a radius of $200-\mu \mathrm{m}$ dorsal-lateral had $5 \%$ connection probability; see text). (4) Inhibitory connections were provided to all cells within a radius of $100 \mu \mathrm{m}$ from the interneuron, with $20 \%$ connection probability. Inhibitory connectivity changed as a function of distance and direction (see text). (5) Excitatory connections in the horizontal plane prevalently ran in the lateromedial direction. The connection probability was a function of the distance between the cells $(5 \%-17 \%$ connectivity was changed depending on the distance of $50-800 \mu \mathrm{m}$ in lateromedial direction, and $2 \%-5 \%$ connectivity for those separated by $50-400 \mu \mathrm{m}$ in mediolateral direction). (6) Interneuron-principal cell connections were higher in the mediolateral direction ( $8 \%-20 \%$ connectivity was assumed for those separated by $0-600 \mu \mathrm{m})$ than in the lateromedial direction $(5 \%-20 \%$ connectivity was assumed for those separated by $0-600 \mu \mathrm{m}$ ). (C) Fear conditioning protocol. As in the experiments of Repa et al. (2001), the "behavioral" protocol included habituation, conditioning, and extinction phases, with eight, 16, and 20 trials, respectively.

these two LAd regions. The reader is reminded that the model's intrinsic connectivity was not set arbitrarily but adjusted to reproduce the pattern of intra-LAd connections inferred in a previous electrophysiological study (Samson and Paré 2006). This analysis revealed that the average ratio of excitatory to inhibitory connections for a LAd principal cell was significantly lower in LAdd $(0.84 \pm 0.03)$ than in LAdv $(1.1 \pm 0.04, P<0.0001)$. This difference was even more pronounced between TP cells in LAdd $(1.07 \pm 0.05)$ and LP cells in LAdv $(1.5 \pm 0.08)$.

However, TP and LP cells were similar in other respects. For instance, both types received at least one tone input and most received direct shock inputs (TP, 93\%; LP, 96\%). Yet, a higher proportion of the tone inputs originated from the thalamus for TP cells (86\%) than LP cells (58\%) and the opposite for cortical inputs (TP, 40\%; LP, 91\%; $X^{2}=23.5, P<0.001$ ). Since previous unit recordings in rats have revealed that the CS responsiveness of audi- tory cortical neurons increases slowly during conditioning (Quirk et al. 1997), the latter difference probably contributed to the distinct temporal profiles seen in model TP and LP cells. Consistent with this, ablating cortical inputs to LAdv and LAdd neurons drastically reduced the tone responsiveness of LP cells $(P<0.001)$ (Fig. 6A2), with only marginal effects on TP cells $(P=0.55)$ (Fig. 6A1).

To test whether the differences in intrinsic connectivity between TP and LP cells play a role in shaping their spatial distribution and responsiveness, we carried out additional simulations using a random uniform connectivity (see details in legend of Fig. 6) or by selectively removing all connections from LAdd to LAdv (Fig. 6B). In TP cells, the random uniform connectivity resulted in an unchanged tone responsiveness during habituation but a marked increase by the end of conditioning $(225 \pm 18 \%$, $P<0.0001)$ and late extinction (49 $\pm 4 \%, P<0.05)$ (Fig. 6B1, empty circles and dashed line). In contrast, the tone responses 


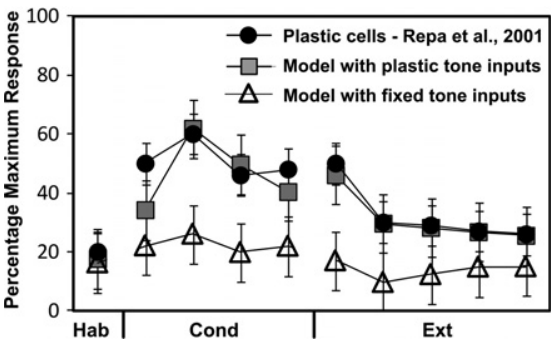

Figure 3. Plasticity of tone inputs is required to generate plastic cells in LAd. With no plasticity in thalamic and cortical inputs, i.e., frequency fixed to $20 \mathrm{~Hz}$, the number of plastic cells decreased $(N=89 / 800)$ and their CS responsiveness also decreased by $61 \pm 3 \%$ (triangles, $P<0.001$ ), compared to experimental (black circles, $N=24 / 100$; data adapted from Repa et al. 2001), and control model (gray squares, $N=198 / 800$ ) values.

of LP cells were reduced by $46 \pm 3 \%(P<0.05)$ during late conditioning and by $37 \pm 3 \%(P<0.01)$ during late extinction, with no significant change during habituation $(P=0.23)$ (Fig. 6B2, empty circles and dashed line). As explained below, these divergent changes in tone responsiveness of TP and LP cells were due to a shift in dorsoventral connectivity. Indeed, by converting the model's connectivity from biology-based to random, the number of ventral to dorsal principal cell connections (which were sparse in the control case) increased, while dorsal to ventral connections (which were high in the control case) decreased.

In a second test, the model's connectivity was returned to its initial state with the exception that we selectively removed all connections from LAdd to LAdv. This resulted in a decrease in tone responses of LP cells during late conditioning ( $43 \pm 3 \%$, $P<0.001)$ and late extinction $(36 \pm 3 \%, P<0.001)$, with no significant change during habituation $(P=0.2)$ (Fig. 6B2, triangles), and, as expected, no significant change in the tone responsiveness of TP cells $(P=0.79)$ (Fig. 6B1, triangles).
Last, we directly tested the hypothesis put forward by Repa et al. (2001), namely that TP and LP cells are involved in the initiation of learning vs. long-term storage of the fear memory, respectively. To this end, we ran simulations with the synaptic strengths of TP cells clamped at habituation levels (by disabling plasticity) during conditioning (Fig. 7A1). Although this manipulation only had a marginal effect on the number of LP cells (from 102 to 98), it greatly reduced their responses to the CS (Fig. 7A2) during late conditioning ( $41 \pm 3 \%$ from control, $P<0.001)$ and late extinction $(29 \pm 3 \%, P<0.001)$. Overall, these simulations support the model set forth by Repa et al. (2001) and indicate that that the heterogeneous intrinsic connectivity of LAd plays a critical role in shaping the behavior of LAd neurons during fear conditioning.

\section{Role of afferent and intrinsic LAd synapses in storing fear memories}

Overall, the model experiments presented so far suggest that formation of auditory conditioned fear memories depends on several interacting factors, including (1) conditioning-induced increases in the tone responsiveness of afferent thalamic and cortical neurons, (2) a heterogeneous termination pattern of these cells in LAd, and (3) spatially differentiated intrinsic connections within LAd. However, the above tests did not address the question of which amygdala synapses are critical for storing the fear memory. As mentioned above, when the tone-evoked activity of thalamic and cortical neurons was artificially returned to habituation levels during the recall test, the number of plastic LAd cells as well as the magnitude of their tone-evoked responses were essentially unaltered (Fig. 4C). This indicates that a population of synapses within the amygdala maintains the memory.

Candidate synapses include those between tone afferents and LAd neurons as well as those between LAd neurons themselves. To identify the critical synapses, we next ran simulations where, after
A1

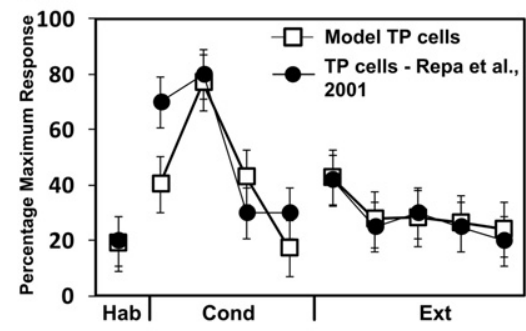

A2

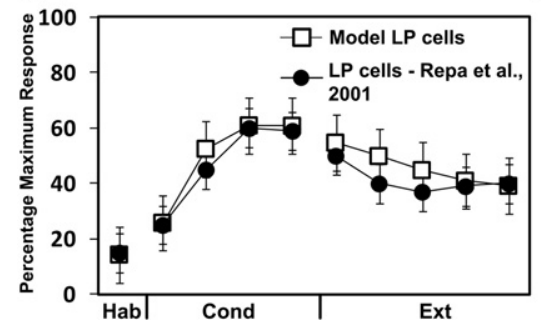

B1

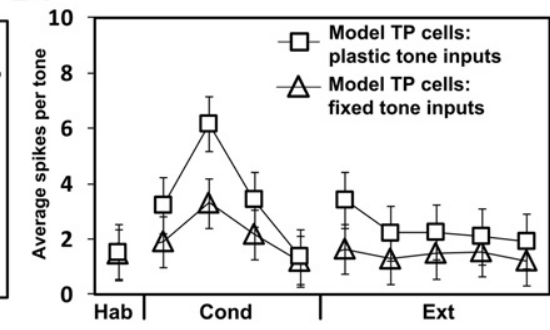

B2

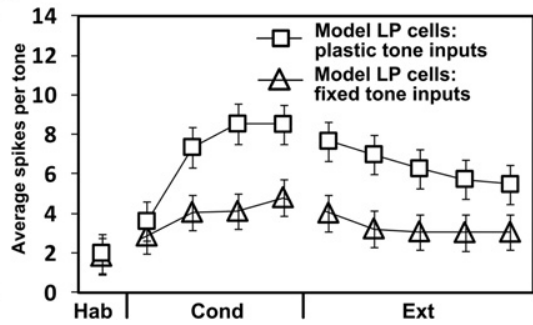

C1

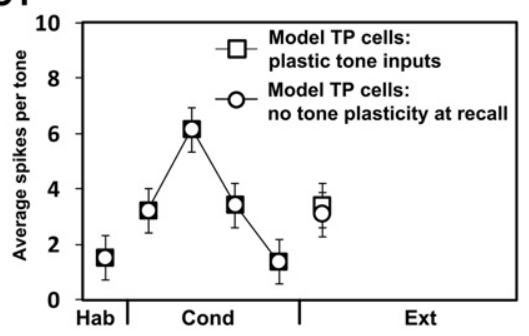

C2

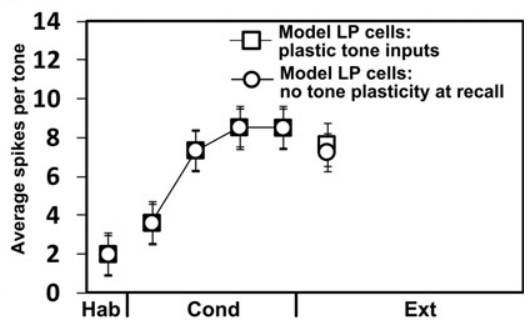

Figure 4. Impact of various manipulations $(A-C)$ on the tone responses of TP $(A 1-C 1)$ and $L P(A 2-C 2)$ cells. $(A)$ Tone responses of $L A d$ cells during the different phases of the behavioral protocol. ( $A 7$ ) Model (squares, $N=96 / 800$ ) and experimental (black circles, $N=12 / 100$; data adapted from Repa et al. 2001) tone responses of TP cells show a sudden increase during early conditioning, and then drop to habituation levels during late conditioning. (A2) Model (squares; $N=102 / 800$ ) and experimental (filled circles; $N=12 / 100$ ) tone responses of $L P$ cells increase gradually with conditioning and persist during extinction. (B) Tone responsiveness of model TP (B1) or LP (B2) cells with plasticity (squares) or without plasticity (triangles) at tone inputs. Data shown include only cells where conditioning induced significant changes in CS responsiveness, using the criterion in Repa et al. (2001). (C) Tone responsiveness of model TP (C1) or LP (C2) cells in two conditions: with plasticity of tone inputs during conditioning and the recall test (squares, from $20 \mathrm{~Hz}$ to $40 \mathrm{~Hz}$ ) or only during conditioning (circles). In the latter case, tone inputs were returned to habituation levels (20 Hz) during the recall test. 


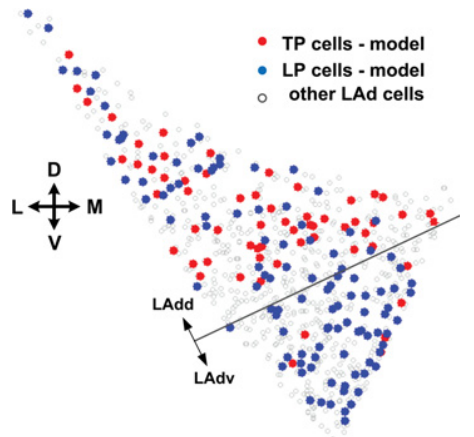

Figure 5. Coronal view of LAd showing the location of TP cells (red) and LP cells (blue) in LAd. The distribution of TP and LP cells was similar to that seen experimentally (see Fig. 8 in Repa et al. 2001).

fear conditioning, the weight of various types of synapses was returned to habituation levels, one type at a time. We then examined the impact of these manipulations on the responsiveness of TP and LP cells when the CS was presented alone. As shown in Figure $7 \mathrm{~B}$, returning the weight of tone afferents to habituation levels had a dramatic impact, reverting the tone evoked responses of TP and LP cells to pre-training levels (paired $t$-tests: TP $66 \pm 5 \%$, $P<0.001$; LP $80 \pm 6 \%, P<0.001$ ). In contrast, the same manipulation at all amygdala synapses simultaneously caused a marginal increase in the tone responses of TP cells $(26 \pm 2 \%)$ and LP cells $(11 \pm 1 \%)$ (Fig. 7C). Only the former effect reached significance (paired $t$-test, $P<0.01$ ). Importantly, restricting the latter tests to synapses involving plastic cells yielded the same results.

\section{Selection of model parameters}

As cited in Materials and Methods, available biological data were used to constrain the single-cell models, connectivity, and the effects of neuromodulation, as in other similar models (e.g., Dyhrfjeld-Johnsen et al. 2007). However, synaptic strengths and plasticity parameters are not well understood presently. Two conditioning-induced factors affect afferent (thalamus/cortex to LAd) and intrinsic (within LAd) plasticity during conditioning: (1) change in excitability of thalamic and cortical cells and (2) change in neuromodulator concentrations. As we have demonstrated with the model, these two factors were critical for matching experimental data in Repa et al. (2001) for the numbers of plastic cells and the magnitudes of their tone responses. Various modifications to other parameters, such as distributions of afferents, plasticity parameters, or intrinsic connectivity within LAd, failed to reproduce the experimental data for the numbers of plastic cells and/or their tone responsiveness (e.g., Supplemental Figs. S2, S3) if only one effect was present. Furthermore, with both effects present, we did find a second model (model 2, see Supplemental Section S2.2) that was similar in all respects to the present model except for different intra-LAd parameters (initial intra-synaptic strengths and plas- ticity parameters). Model 2 outputs were also similar in all cases except for decreased inhibitory transmission in the amygdala after fear conditioning as has been reported in some experiments (Rea et al. 2009), in contrast to the small increase seen in model 1. Both thalamic/cortical plasticity and neuromodulator effects were critical for model 2 also. Taken together, all these constitute evidence that the network might not be inadvertently "tuned" in the process of development.

\section{Discussion}

We have developed a biophysically realistic model of LAd to shed light on fundamental, yet unresolved, questions regarding the mechanisms of Pavlovian fear memory formation, storage, and expression. These questions include the respective contributions of plasticity in LAd vs. CS afferent pathways, and the role of the intrinsic LAd network in the initiation and storage of fear memories. Below, we discuss the insights that emerged from our simulations.

\section{Initiation vs. storage of fear memory by different types of LAd neurons: contributing mechanisms}

During fear conditioning, the temporal profile of changes in CS responsiveness is not uniform in LAd (Repa et al. 2001). Some neurons, concentrated in LAdd, display augmented CS responses for only a few trials whereas others, typically in LAdv, show persistently increased CS responses that resist extinction. This led Repa et al. (2001) to speculate that the two cell types (transient $[\mathrm{TP}]$, long-term [LP]) are involved in the initiation of learning vs. long-term storage of the fear memory, respectively. Our model could reproduce these observations including the two cell types, their incidence, as well as differential distribution in LAd. Our analyses revealed that a number of interacting factors contributed to the emergence of the two cell types in LAd.

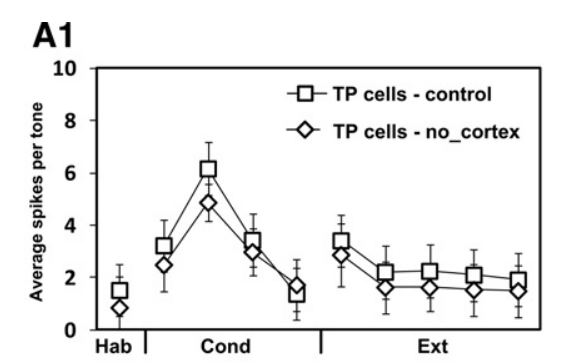

A2

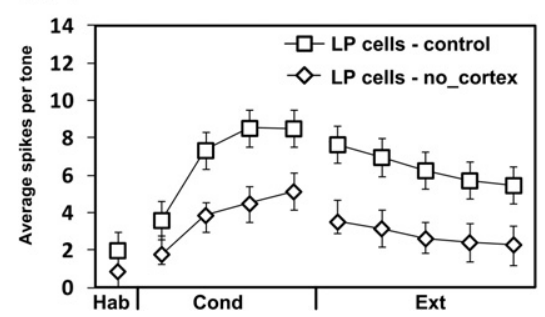

B1

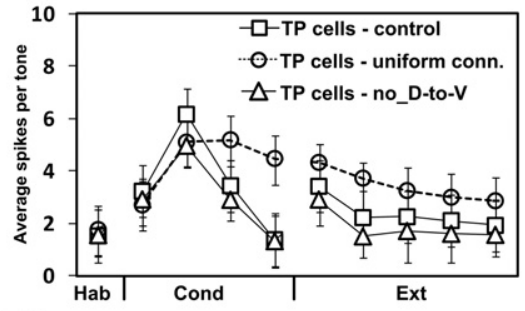

B2

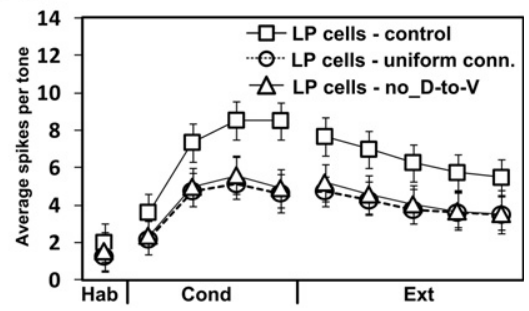

Figure 6. (A) Cortical inputs are necessary for the formation of LP cells. Spikes per tone (mean \pm SEM) of plastic LAd model cells. TP $(A 1)$ and LP (A2) cells, for the following cases: control (square) and no cortical input (diamond). (B) Intrinsic connectivity contributes to the generation of the two cell types in LAd. Spikes per tone (mean \pm SEM) of LAd model cells. TP (B1) and LP (B2) cells, for the following cases: control (squares), uniform connectivity (circles, see below), and no LAdd to LAdv connectivity (triangles). Random uniform connectivity was implemented as follows: $3 \%$ excitatory connectivity within a 50 - to $400-\mu \mathrm{m}$ radius of a principal cell, and a $35 \%$ inhibitory connectivity within a 50 - to $200-\mu \mathrm{m}$ radius for an interneuron, resulting in average excitatory and inhibitory connections per principal cell of 21.25 and 20.05, respectively. This ensured that the average excitatory and inhibitory connections to principal cells matched the control case values of 21.4 and 22.2 , respectively. 
A1

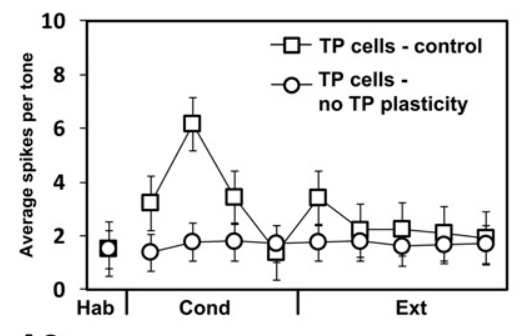

A2

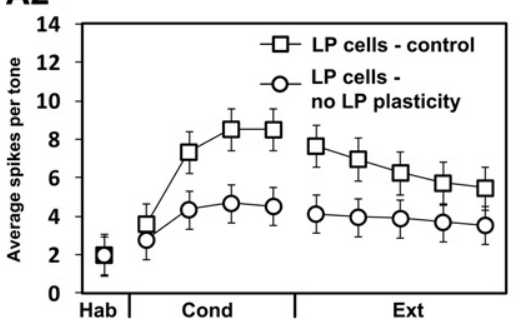

B1

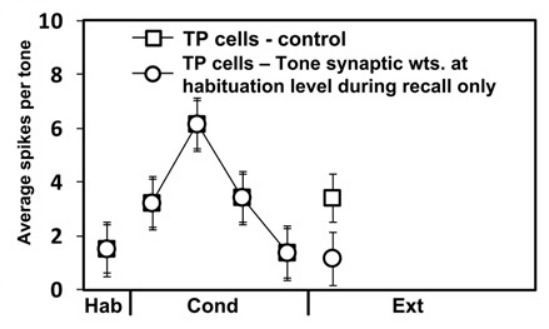

B2

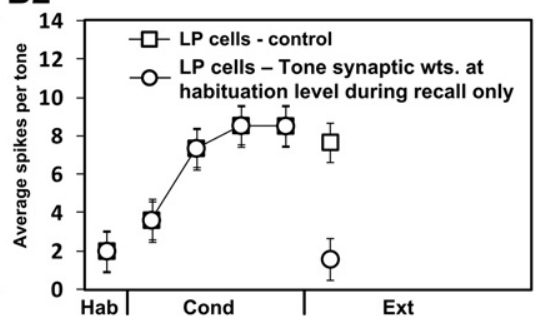

C1

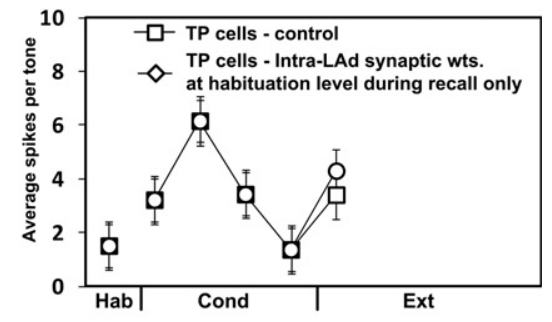

C2

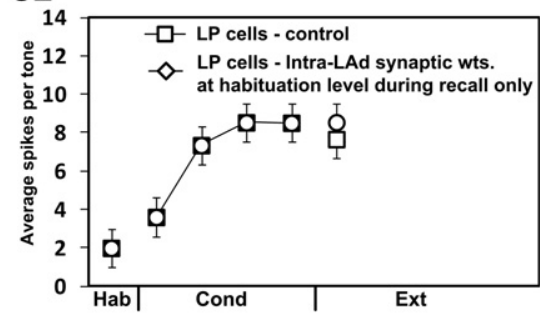

Figure 7. (A) Clamping the tone responses of TP cells at habituation levels alters the impact of fear conditioning on LAd cells. Model tone responses in control conditions (squares), or when the tone responses of TP cells were maintained at habituation levels (circles). (B) Model tone responses decrease considerably when the tone-pyr weights are set to habituation levels during the recall test (circles). (C) Model tone responses are largely unaltered when the synaptic weights between neurons within LAd are set to habituation levels during recall (circles).

\section{Intrinsic connectivity}

Differences in the intrinsic connectivity of principal cells in LAdd and LAdv appeared to play a determining role in the emergence of TP and LP cells. Indeed, our model featured heterogeneous intrinsic connections based on the findings of a prior electrophysiological study (Samson and Paré 2006). As a result of this heterogeneous connectivity, the ratio of excitatory to inhibitory inputs to principal cells was lower in LAdd than in LAdv, and this difference was particularly marked between TP and LP cells. When this heterogeneous intrinsic connectivity was replaced with random uniform connections, the model could no longer reproduce the observations of Repa et al. (2001). LAdd to LAdv connections appeared to play a critical role in this respect since selective ablations of these connections greatly attenuated the CS responsiveness of LP cells. Moreover, in support of the notion that TP and LP cells are, respectively, involved in the initiation of learning vs. long-term storage of the fear memory, we observed that clamping the CS responsiveness of TP cells at habituation levels during learning blunted the increase in the CS responses of LP cells produced by fear conditioning.

\section{Tone and shock inputs}

Another aspect of the model's connectivity that played a determining role was the distribution of tone and shock inputs. Compared to nonplastic cells, a higher proportion of TP and LP cells received tone and shock inputs in the model. However, TP and LP cells tended to derive their tone inputs from different sources: prevalently from the thalamus for TP cells vs. the cortex for LP cells. Since the CS responsiveness of auditory cortical neurons increases slowly during conditioning (Quirk et al. 1997), this difference is likely a major determinant of the contrasting temporal profiles of increased CS responsiveness seen in model TP and LP cells.

\section{Contributions of the amygdala and CS afferent neurons to fear memory formation and storage}

Despite incontrovertible evidence that fear conditioning leads to plasticity not only in the amygdala but also in CS afferent path- ways ( $\sim 25$ papers from numerous laboratories), the role of thalamic and cortical neurons in fear memory formation is often overlooked in the literature (for review, see Weinberger 2011). In part, this is due to the difficulty of disentangling thalamocortical vs. amygdala contributions to fear memory. However, computational models allow experimentally impossible manipulations that can shed light on this question.

Here, we compared how our model LAd network behaved when the firing rates of thalamic and cortical neurons during the CS were clamped at habituation levels throughout the behavioral protocol or allowed to increase during conditioning, as observed experimentally. These simulations revealed that unless thalamic and cortical CS responsiveness increased during conditioning, the model could not reproduce learning-induced changes in the behavior of LAd neurons, as observed experimentally (Repa et al. 2001). While this suggests that an augmented thalamic and cortical CS responsiveness is required for the induction of amygdala plasticity, is it also required for fear expression after learning? To address this question, we allowed the CS responsiveness of thalamic and cortical neurons to increase during conditioning but returned it to habituation levels during the recall test. Unexpectedly, the CS responses of LAd neurons were marginally altered by this manipulation.

Overall, these results support the view that increases in the CS responsiveness of thalamic and cortical neurons are required for fear learning, but that later on they are no longer critical because the fear memory can be maintained by learning-induced changes in synaptic efficacy within the amygdala. To identify what populations of synapses are critical for storing Pavlovian fear memories, we next ran simulations where, after fear conditioning, the weight of various types of synapses was returned to habituation levels, one type at a time. This revealed that the critical sites of plasticity are tone inputs from the thalamus and cortex to LAd neurons. Indeed, suppressing plasticity at these synapses returned the tone responses of TP and LP cells to habituation levels. In contrast, abolishing plasticity at all synapses between amygdala neurons caused an unexpected increase in CS responsiveness. It may be that plasticity in the intrinsic LAd network leads to a potentiation of feedforward inhibition that limits the 
size of the population of plastic cells. Such a phenomenon might contribute to maintain the specificity of fear memories. A challenge for future studies will be to test this prediction.

Finally, it should be noted that the model did not address the question of whether the amygdala is involved in altering the tone responsiveness of thalamic and/or cortical neurons in the first place. This possibility appears likely given the abundance of data indicating that the amygdala can facilitate synaptic plasticity in various structures of the brain either directly, or via the recruitment of modulatory systems (McGaugh 2002; Paré 2003).

The results of our model experiments lead to the following two predictions. First, that interference with plasticity of thalamic and cortical CS input neurons will prevent the emergence of plastic LAd cells and formation of the conditioned fear memory. Second, that if activity of CS input neurons is normal during training but returned to preconditioning levels during testing, the number and distribution of TP and LP cells, as well as the expression of conditioned fear, will be normal. While we recognize that testing these predictions will be challenging, recent advances in optogenetics and genetic engineering (see Supplemental Section S2.3) suggest that it will soon be possible.

\section{Materials and Methods}

We developed a biophysical model of LAd. A brief overview is presented here. See Supplemental Material, Sections S1-S3, for details.

\section{Single-cell models}

To reproduce the diversity of spike frequency adaptation seen in principal LA neurons (for review, see Sah et al. 2003), we modeled three types of regular spiking principal cells, with high (type-A), intermediate (type-B), or low (type-C) spike frequency adaptation, due to the differential expression of a $\mathrm{Ca}^{2+}$-dependent $\mathrm{K}^{+}$current. LA also contains local GABAergic interneurons that exhibit various firing patterns, even among neurochemically homogeneous subgroups (Lang and Paré 1998; Rainnie et al. 2006; Sosulina et al. 2006; Woodruff and Sah 2007; Jasnow et al. 2009). However, the majority displays a fast-spiking pattern, which was reproduced in the model.

The principal cell model had three compartments representing a soma (diameter $24.75 \mu \mathrm{m}$, length $25 \mu \mathrm{m}$ ), an apical dendrite (diameter $2.5 \mu \mathrm{m}$, length $296 \mu \mathrm{m}$ ) on which synapses were placed, and another dendrite (diameter $5 \mu \mathrm{m}$, length $119 \mu \mathrm{m}$ ) that helped match passive properties. Values of specific membrane resistance, membrane capacity, and cytoplasmic (axial) resistivity were, respectively, $R_{\mathrm{m}}=55 \mathrm{~K} \Omega-\mathrm{cm}^{2}, C_{\mathrm{m}}=1.2-2.4 \mu \mathrm{F} / \mathrm{cm}^{2}$, and $R_{\mathrm{a}}=$ $150-200 \Omega$-cm. Leakage reversal potential $\left(E_{\mathrm{L}}\right)$ was set to -67 $\mathrm{mV}$. The resulting $V_{\text {rest }}$ was $-69.5 \mathrm{mV}$, input resistance $\left(R_{\mathrm{IN}}\right)$ was $\sim 150 \mathrm{M} \Omega$, and $\tau_{\mathrm{m}}$ was $30 \mathrm{msec}$, all of which were within the ranges reported in previous physiological studies (Washburn and Moises 1992; Faber et al. 2001). All compartments had the following currents: leak $\left(I_{\mathrm{L}}\right)$, voltage-gated persistent muscarinic $\left(I_{\mathrm{M}}\right)$, highvoltage activated $\mathrm{Ca}^{2+}\left(I_{\mathrm{Ca}}\right)$, spike-generating sodium $\left(I_{\mathrm{Na}}\right)$, potassium delayed rectifier $\left(I_{\mathrm{DR}}\right)$, and A-type potassium $\left(I_{\mathrm{A}}\right)(\mathrm{Li}$ et al. 2009; Power et al. 2011). In addition, the dendrites had a hyperpolarization-activated nonspecific cation $\left(I_{\mathrm{h}}\right)$ current and a slow apamin-insensitive, voltage-independent afterhyperpolarization current $\left(I_{\mathrm{SAHP}}\right)$ (Power et al. 2011). See Supplemental Sections S1.4 and S1.5 as well as Supplemental Tables S1 and S2 for current equations and densities.

Figure 1A shows the voltage response of the three principal cell models to depolarizing (two left panels) and hyperpolarizing (right panel) current injection. The three model cells could reproduce previous experimental observations (Sah et al. 2003) including the temporal dynamics of repetitive firing produced by membrane depolarization as well as their responses to membrane hyperpolarization.
The interneuron model had two compartments, a soma (diameter $15 \mu \mathrm{m}$, length $15 \mu \mathrm{m}$ ) and a dendrite (diameter 10 $\mu \mathrm{m}$, length $150 \mu \mathrm{m})$. Each compartment contained a fast $\mathrm{Na}^{+}$ $\left(I_{\mathrm{Na}}\right)$ and a delayed rectifier $\mathrm{K}^{+}\left(I_{\mathrm{DR}}\right)$ current with kinetics (Durstewitz et al. 2000) that reproduced the much shorter spike duration that is characteristic of fast-spiking cells. The passive membrane properties were as follows: $R_{\mathrm{m}}=20 \mathrm{~K} \Omega-\mathrm{cm}^{2}, C_{\mathrm{m}}=1.0$ $\mu \mathrm{F} / \mathrm{cm}^{2}, R_{\mathrm{a}}=150 \Omega-\mathrm{cm}$, and $E_{\mathrm{L}}=-70 \mathrm{mV}$. As shown in Figure $1 \mathrm{~B}$, the interneuron model could reproduce the nonadapting repetitive firing behavior of fast spiking cells, as observed experimentally (Lang and Paré 1998; Woodruff and Sah 2007).

\section{Network structure and connectivity}

It was estimated that there are 24,000 principal cells in LAd (Tuunanen and Pitkänen 2000). To keep computation times practical while capturing the complexity of the intra-LAd network, we modeled a scaled down (30:1) version of LAd that included 800 principal cells (types A, B, and C in the ratio 50:30:20). Because the proportion of interneurons to principal cells is 20:80 (McDonald and Augustine 1993), the model included 200 interneurons. Principal cells and interneurons were distributed randomly in a realistic tridimensional representation of the hornshaped LAd (Fig. 2A).

By comparing the responses of LA cells to local applications of glutamate at various positions with respect to recorded neurons, Samson and Paré (2006) inferred general principles of connectivity among principal cells, as well as between local-circuit and principal neurons. In particular, Samson and Paré (2006) determined that excitatory connections between principal cells prevalently run ventrally and medially with significant rostrocaudal divergence. In contrast, inhibitory connections prevalently run mediolaterally in the horizontal plane and have no preferential directionality in the coronal plane. Samson and Paré (2006) also recognized that principal LA neurons located along the external capsule (in the "shell" region of LA) form different connections than those found more medially (in the "core" region of LA; shell thickness of $100 \mu \mathrm{m}$ ). In the shell region, inhibitory neurons only affect nearby principal neurons whereas excitatory connections between principal cells are spatially less limited. Although not providing precise connectivity data, this information could be used to infer critical estimates about directionality and ratio of excitation to inhibition. Using the directionality information from the Samson and Paré (2006) study, and a third of the connectivity numbers, a model principal cell had, on average, 21.4 mono- and 40.6 disynaptic excitatory inputs, and 22.2 monosynaptic inhibitory inputs. These average figures result from the implementation of directionally heterogeneous connections, as described below.

\section{Coronal plane}

Within a 100- $\mu \mathrm{m}$ coronal slice, principal shell neurons excite shell cells located 300-400 $\mu \mathrm{m}$ more ventrally with $10 \%$ probability (note that these are for monosynaptic connectivity) (Fig. 2B1). Core to shell connections occur with a much lower probability (2\%). In addition, principal shell neurons are inhibited by more dorsally located interneurons (23\% connectivity for cells within $300 \mu \mathrm{m}$ ) (Fig. 2B2). In the core region, excitatory connections between principal cells have a greater extent in the lateromedial direction (50-800 $\mu \mathrm{m}, 2 \%-6 \%$ connectivity) (Fig. 2B3) than in the mediolateral direction (50-200 $\mu \mathrm{m}, 5 \%$ connectivity) (Fig. 2B3), whereas inhibitory connections have similar strengths in all directions (interneurons formed inhibitory inputs with $10 \%-24 \%$ of principal cells at a distance of 50-600 $\mu \mathrm{m}$ ) (Fig. 2B4).

\section{Horizontal plane}

Within a $100-\mu \mathrm{m}$ horizontal slice, connections were set in the following manner. Connection probability increased with distance for lateromedial connections, and the opposite for mediolateral connections (see details in Fig. 2B5). As to inhibitory connections, they prevalently run in the mediolateral direction with $8 \%-20 \%$ connectivity in the range 50-600 $\mu \mathrm{m}$ and $5 \%-20 \%$ connectivity 
in the lateromedial direction within a distance of 50-600 $\mu \mathrm{m}$ (Fig. 2B6). Principal cells project to all interneurons within a spherical radius of $100 \mu \mathrm{m}$.

\section{Activity-dependent synaptic plasticity}

Fear conditioning induces changes in the efficacy of synapses conveying CS inputs to LA (McKernan and Shinnick-Gallagher 1997; Rumpel et al. 2005). Also, activity-dependent long-term potentiation (LTP) can be induced at thalamic (Huang et al. 2000; Tsvetkov et al. 2004; Humeau et al. 2005) and cortical (Huang and Kandel 1998; Tsvetkov et al. 2002; Humeau et al. 2003, 2005) inputs to principal LA neurons. Furthermore, it has been shown that fear conditioning and LTP share a common set of mechanisms (Miserendino et al. 1990; Kim et al. 1991; Campeau et al. 1992; Huang and Kandel 1998; Bauer et al. 2002), and that fear conditioning occludes LTP of cortical inputs to LA cells (Tsvetkov et al. 2002). These findings, coupled to the fact that intraamygdala infusion of NMDA receptor antagonists blocks the induction of conditioned fear in vivo and of LTP in vitro, provided the basis for the hypothesis that NMDA receptor-mediated LTP represents a cellular substrate of fear conditioning (for review, see Pape and Paré 2010). Induction of LTP at thalamic and cortical inputs to principal cells has been found to depend on postsynaptic depolarization allowing influx of $\mathrm{Ca}^{2+}$ ions via NMDA receptors (Bauer et al. 2002; Tsvetkov et al. 2002) and/or voltagedependent L-type $\mathrm{Ca}^{2+}$ channels (Weisskopf et al. 1999; Bauer et al. 2002; Humeau et al. 2005). In addition, it was reported that excitatory glutamatergic synapses from the thalamus or cortex onto interneurons exhibit NMDA-receptor-dependent potentiation (Bauer and LeDoux 2004). This potentiation is also AMPA-receptor-dependent because AMPA receptors on inhibitory neurons lack the GluR2 subunit, making them calcium-permeable (Mahanty and Sah 1998). It was further shown that inhibitory inputs onto pyramidal cells are modifiable via a $\mathrm{Ca}^{2+}$-dependent mechanism (Bauer and LeDoux 2004). In addition to LTP, longterm depression (LTD) can be readily induced at excitatory amygdala synapses by low-frequency stimulation of the lateral nucleus at $1 \mathrm{~Hz}$ for 15 min (Wang and Gean 1999).

To reproduce these experimental findings, all AMPA synapses in the model were endowed with long-term postsynaptic plasticity except for those delivering shock or background inputs. Also, all GABA synapses had long-term plasticity. This form of plasticity was implemented using a learning rule that uses the concentration of a postsynaptic calcium pool at each modifiable synapse (Kitajima and Hara 1997; Shouval et al. 2002; Li et al. 2009). Calcium entered postsynaptic pools at excitatory synapses via NMDA receptors (and AMPA receptors for interneurons) and voltage-gated calcium channels (VGCCs). Similarly, calcium for pools at inhibitory synapses came from postsynaptic intracellular stores and VGCCs (Li et al. 2009). For both types of synapses, the synaptic weight decreased when the calcium concentration of the pool was below a lower threshold and increased when it exceeded an upper threshold. Equations and details related to the learning rule are provided in Supplemental Section S1.6.

All model AMPA and GABA synapses also exhibited shortterm presynaptic plasticity, with short-term depression at interneuron to principal cell and principal cell to interneuron connections modeled after the experimental findings of Woodruff and Sah (2007) in the basolateral amygdala. In the absence of experimental data about the short-term dynamics of synapses between principal LAd neurons, we relied on data obtained between regular spiking cortical cells to implement short-term frequencydependent depression (Markram et al. 2004). For convenience in modeling, these were implemented by multiplying the synaptic conductances of the relevant AMPA and GABA synapses after each spike with appropriate frequency-dependent factors (Varela et al. 1997). See Supplemental Section S1.7 for equations.

\section{Neuromodulator effects}

Neuromodulators have long been implicated in fear and anxiety, and are known to regulate Pavlovian fear learning and synaptic plasticity in LA (Tully and Bolshakov 2001; Bissière et al. 2003). Conditioned aversive stimuli alter the activity of ventral tegmental area and locus coeruleus neurons (Feenstra et al. 2001), which in turn modulate fear and anxiety through their widespread forebrain projections, including to the amygdala (Guarraci and Kapp 1999). Therefore, the model incorporated the effects of dopamine (DA) and norepinephrine (NE) on LAd cells, based on prior experimental reports, as outlined in Supplemental Section S1.1.

\section{Inputs}

LA receives auditory inputs directly from the posterior intralaminar nucleus and the medial sector of the medial geniculate nucleus (LeDoux et al. 1985; Turner and Herkenham 1991; Shinonaga et al. 1994; Linke et al. 2000; Woodson et al. 2000) as well as indirectly via temporal auditory cortical fields (Mascagni et al. 1993; Romanski and LeDoux 1993a,b; Shi and Cassell 1997). Moreover, the same posterior thalamic regions that send auditory inputs to LA also receive inputs from the spinothalamic tract (LeDoux et al. 1987) and probably send convergent CS and US inputs to LA. Accordingly, the model was endowed with CS and US inputs represented as glutamatergic synapses acting at AMPA and NMDA receptors. Based on the experimental literature, we modeled two types of CS inputs: thalamic and cortical, both at $20 \mathrm{~Hz}$ during habituation and $40 \mathrm{~Hz}$ after conditioning (Bordi and LeDoux 1994; Quirk et al. 1997). These two tone inputs were differentially distributed in LAd, as described below.

\section{Background synaptic inputs}

LA projection neurons have low spontaneous firing rates in control conditions (Gaudreau and Paré 1996). To reproduce this, Poisson-distributed, random excitatory background inputs were delivered to all model cells, resulting in average spontaneous firing rates of $0.7 \mathrm{~Hz}$ for principal cells and $7.2 \mathrm{~Hz}$ for interneurons.

\section{Tone and shock inputs}

Auditory fear conditioning is commonly thought to depend on the convergence of inputs relaying information about the CS (tone) and US (footshock) in LA (for review, see Pape and Paré 2010). In the model, the CS and US inputs were represented by glutamatergic synapses acting via AMPA and NMDA receptors. The frequency of thalamic and cortical tone inputs during habituation was set to $20 \mathrm{~Hz}$ (Quirk et al. 1997). The tone inputs also included noise represented by random Poisson spikes with an average frequency of $2 \mathrm{~Hz}$. The density of both cortical and thalamic tone inputs to LAd was determined iteratively (see Supplemental Section S1.2). The following distribution of inputs was used for the simulations described in the Results section: uniform total tone density throughout LAd with $70 \%$ of the LAdd cells receiving thalamic and $35 \%$ receiving cortical tone projections, and the opposite for LAdv, i.e., 35\% of LAdv cells receiving thalamic and 70\% receiving cortical tone projections. The shock inputs continued to be distributed uniformly to $70 \%$ of LAd cells.

\section{Conditioning protocol used in simulations}

The schedule of tone and shock inputs in the simulations was based on in vivo studies (Quirk et al. 1995; Repa et al. 2001). We scaled down the timing of the auditory fear conditioning protocol so that it would be suitable for computational studies (Fig. 2C). The protocol included three phases (habituation, conditioning, and extinction), comprised of 8, 16, and 20 trials, respectively. Each trial featured a 0.5 -sec tone CS followed by a 3.5-sec gap. Only during conditioning, a shock was administered $100 \mathrm{msec}$ prior to the end of the tone, so that they co-terminated. In light of evidence that fear conditioning leads to plasticity in CS afferent pathways (for review, see Weinberger 2011), the frequency of thalamic and cortical tone inputs was increased to $40 \mathrm{~Hz}$ after the first and sixth conditioning trials, respectively. Simulations were performed using the NEURON modeling package (Carnevale and Hines 2006). 


\section{Model tuning and validation}

To obtain the full model, several aspects had to be developed: the single-cell models, the properties of glutamatergic and GABAergic synapses, the intrinsic connections between LAd cells, plasticity of these connections, neuromodulatory inputs, and, finally, extrinsic inputs conveying shock and CS information. For each of these aspects, the following multistep approach was used. (1) The experimental literature was mined, both to constrain the modeling and derive criteria to assess whether the model successfully reproduced the particular phenomena being modeled. (2) Iterative "tuning" of model parameters was performed until the model's behavior matched experimental observations. (3) Validation of the model took two forms. First, the ability of the model component to reproduce earlier experimental observations, as described in the previous sentence. Second, the ability of the model component to reproduce a set of experimental observations it was not designed to reproduce.

Here, it should be noted that because the model includes 1000 neurons connected by nearly 40,000 synapses, it was not possible to tune each component to achieve reproduction of the results of Repa et al. (2001). For instance, development of the single-cell models was based on biophysical studies of the intrinsic properties of LAd neurons. The design of single-cell models aimed to reproduce these observations without forethought as to the consequences of the model's properties for fear conditioning. Similarly, the 40,000 synapses connecting these cells were not adjusted individually in anticipation of their potential impact on the responsiveness of LAd neurons during fear conditioning. Rather, probabilistic gradients of connectivity were implemented to reproduce the findings of an in vitro study that inferred how the intrinsic LA network is organized based on responses evoked by local pressure applications of glutamate (Samson and Paré 2006). Similarly, the approach used to adjust properties of synaptic plasticity did not aim to predispose the network to reproduce the differential distribution of plastic cells reported in Repa et al. (2001). Instead, properties of plasticity were adjusted so that the synapses could undergo activity-dependent plasticity, as observed experimentally, while maintaining overall network stability by avoiding runaway behavior. Overall, $\sim 75 \%$ of the model was based on lower level details, very remote from the higher levels of conditioning-induced tone responses. Therefore, model tuning up to the point of assembling the entire network could not be done to achieve a specific impact on higher level responses.

The assembled network model was then tuned in two steps. In the first step, the initial weights of the synapses (tone, shock, intrinsic connections) and the background input parameters were adjusted to reproduce experimentally observed spontaneous firing rates for principal cells and interneurons. In the second step, the model was subjected to the training protocol (Fig. 2C), and the plasticity (learning in AMPA and GABA synapses) and neuromodulation (DA and NE) parameters, as well as the distribution of afferent inputs (see Supplemental Section S1.2), were adjusted to reproduce both the numbers of plastic (TP and LP) cells and their tone responses as reported in experiments (Repa et al. 2001). Adjustments to parameters at this step were consistent with biological bounds where available in the literature (see Supplemental Tables S1-S4). Note that step 2 does not affect step 1. Iteration was involved between the two steps. Surprisingly, the tuning was not difficult and the model output matched data in Repa et al. (2001) very well. Specifically, average values of model tone responses in trial blocks were within $98 \%$ of the experimental values (Fig. 4A1,A2). Also, the fraction of model plastic cells (198/ $800=25 \%)$ compared well with experimental estimates $(24 \%)$. Given the tuning process described above, we feel that it would not have been possible to predict that the model would reproduce these experimental observations, let alone so closely.

We validated the full model by testing its ability to reproduce a set of experimental observations it was not designed to reproduce: the impact of blocking NA and DA receptors on the acquisition of conditioned fear (Bissière et al. 2003; Rodrigues et al. 2009). That is, we blocked DA and NE effects individually, and found that both interfered with the acquisition of fear memory in LAd (Supplemental Fig. S4), consistent with experimental reports (Bissière et al. 2003; Rodrigues et al. 2009). As additional validation of the model, we found that the distribution of model TP and LP cells (Fig. 5) matched experimental reports in Repa et al. (2001) even though we performed no model tuning to achieve this effect. Furthermore, to ensure that the model outputs were consistent across random runs using the same network size, we ran three additional cases with different (1) distribution of cells (types A, B, C) in the 3D space, (2) connectivity, and (3) delays, all selected with different random seeds. All these cases yielded consistent numbers for the total plastic cells in the control case (avg. 196.6 \pm 4 ), and for the individual cell groups: TP cells (93.6 \pm 4.1$)$, LP cells (103 \pm 1.7$)$. Moreover, all the other behaviors discussed were similar, suggesting that the model output is robust to all these parameters.

\section{Acknowledgments}

This research was supported in part by NIMH grants MH083710 to D.P. and MH087755 to S.S.N.

\section{References}

Bauer EP, LeDoux JE. 2004. Heterosynaptic long-term potentiation of inhibitory interneurons in the lateral amygdala. J Neurosci 24: 9507-9512.

Bauer EP, Schafe GE, LeDoux JE. 2002. NMDA receptors and L-type voltage gated calcium channels contribute to long-term potentiation and different components of fear memory formation in the lateral amygdala. I Neurosci 22: 5239-5249.

Bissière S, Humeau Y, Luthi A. 2003. Dopamine gates LTP induction in lateral amygdala by suppressing feedforward inhibition. Nat Neurosci 6: $587-592$.

Bordi F, LeDoux JE. 1994. Response properties of single units in areas of rat auditory thalamus that project to the amygdala. I. Acoustic discharge patterns and frequency receptive fields. Exp Brain Res 98: 261-274.

Campeau S, Miserendino MJD, Davis M. 1992. Intraamygdala infusion of the $N$-methyl-D-aspartate receptor antagonist AP5 blocks acquisition but not expression of fear-potentiated startle to an auditory conditioned-stimulus. Behav Neurosci 106: 569-574.

Carnevale NT, Hines ML. 2006. The NEURON book. Cambridge University Press, Cambridge, UK.

Collins DR, Paré D. 2000. Differential fear conditioning induces reciprocal changes in the sensory responses of lateral amygdala neurons to the $\mathrm{CS}^{+}$)and $\mathrm{CS}^{-}$. Learn Mem 7: 97-103.

Durstewitz D, Seamans JK, Sejnowski TJ. 2000. Dopamine-mediated stabilization of delay-period activity in a network model of prefrontal cortex. J Neurophysiol 83: 1733-1750.

Dyhrfjeld-Johnsen J, Santhakumar V, Morgan RJ, Huerta R, Tsimring L, Soltesz I. 2007. Topological determinants of epileptogenesis in large-scale structural and functional models of the dentate gyrus derived from experimental data. J Neurophysiol 97: 1566-1587.

Faber ES, Callister RJ, Sah P. 2001. Morphological and electrophysiological properties of principal neurons in the rat lateral amygdala in vitro. I Neurophysiol 85: 714-723.

Feenstra MG, Vogel M, Botterblom MH, Joosten RN, de Bruin JP. 2001. Dopamine and noradrenaline efflux in the rat prefrontal cortex after classical aversive conditioning to an auditory cue. Eur J Neurosci 13: $1051-1054$.

Gaudreau H, Paré D. 1996. Projection neurons of the lateral amygdaloid nucleus are virtually silent throughout the sleep-walking cycle. I Neurophysiol 75: 1301-1305.

Goosens KA, Hobin JA, Maren S. 2003. Auditory-evoked spike firing in the lateral amygdala and Pavlovian fear conditioning: Mnemonic code or fear bias? Neuron 40: 1013-1022.

Guarraci FA, Kapp BS. 1999. An electrophysiological characterization of ventral tegmental area dopaminergic neurons during differential Pavlovian fear conditioning in the awake rabbit. Behav Brain Res 99: 169-179.

Hennevin E, Maho C. 2005. Fear conditioning-induced plasticity in auditory thalamus and cortex: To what extent is it expressed during slow-wave sleep? Behav Neurosci 110: 1277-1289.

Huang YY, Kandel ER. 1998. Postsynaptic induction and PKA-dependent expression of LTP in the lateral amygdala. Neuron 21: 169-178.

Huang YY, Martin KC, Kandel ER. 2000. Both protein kinase A and mitogen activated protein kinase are required in the amygdala for the macromolecular synthesis-dependent late phase of long-term potentiation. J Neurosci 20: 6317-6325. 
Humeau Y, Shaban H, Bissiere S, Luthi A. 2003. Presynaptic induction of heterosynaptic associative plasticity in the mammalian brain. Nature 426: $841-845$.

Humeau Y, Herry C, Kemp N, Shaban H, Fourcaudot E, Bissiere S, Luthi A. 2005. Dendritic spine heterogeneity determines afferent-specific Hebbian plasticity in the amygdala. Neuron 45: 119-131.

Jasnow AM, Ressler KJ, Hammack SE, Chhatwal JP, Rainnie DG. 2009. Distinct subtypes of cholecystokinin (CCK)-containing interneurons of the basolateral amygdala identified using a CCK promoter-specific lentivirus. J Neurophysiol 101: 1494-1506.

Johnson LR, Hou M, Prager EM, LeDoux JE. 2011. Regulation of the fear network by mediators of stress: Norepinephrine alters the balance between cortical and subcortical afferent excitation of the lateral amygdala. Front Behav Neurosci 5: 23.

Kim JJ, DeCola JP, Landeira-Fernandez J, Fanselow MS. 1991 $N$-Methyl-D-aspartate receptor antagonist APV blocks acquisition but not expression of fear conditioning. Behav Neurosci 105: 126-133.

Kitajima T, Hara K. 1997. An integrated model for activity-dependent synaptic modifications. Neural Networks 10: 413-421.

Lang EJ, Paré D. 1998. Synaptic responsiveness of interneurons of the cat lateral amygdaloid nucleus. Neurosci 83: 877-899.

LeDoux JE. 2000. Emotional circuits in the brain. Annu Rev Neurosci 23: $155-184$.

LeDoux JE, Sakaguchi A, Iwata J, Reis DJ. 1985. Auditory emotional memories: Establishment by projections from the medial geniculate nucleus to the posterior neostriatum and/or dorsal amygdala. Ann N Y Acad Sci 444: 463-464.

LeDoux JE, Ruggiero DA, Forest R, Stornetta R, Reis DJ. 1987. Topographic organization of convergent projections to the thalamus from the inferior colliculus and spinal cord in the rat. J Comp Neurol 264: 123-146.

Letzkus JJ, Wolff SB, Meyer EM, Tovote P, Courtin J, Herry C, Lüthi A. 2011. A disinhibitory microcircuit for associative fear learning in the auditory cortex. Nature 480: 331-335.

Li G, Nair S, Quirk GJ. 2009. A biologically realistic network model of acquisition and extinction of conditioned fear associations in lateral amygdala neurons. J Neurophysiol 101: 1629-1646.

Linke R, Braune G, Schwegler H. 2000. Differential projection of the posterior paralaminar thalamic nuclei to the amygdaloid complex in the rat. Exp Brain Res 134: 520-532.

Mahanty NK, Sah P. 1998. Calcium-permeable AMPA receptors mediate long-term potentiation in interneurons in the amygdala. Nature 394: 683-687.

Markram H, Toledo-Rodriguez M, Wang Y, Gupta A, Silberberg G, Wu C. 2004. Interneurons of the neocortical inhibitory system. Nat Rev Neurosci 5: 793-807.

Mascagni F, McDonald AJ, Coleman JR. 1993. Corticoamygdaloid and corticocortical projections of the rat temporal cortex: A Phaseolus vulgaris leucoagglutinin study. Neuroscience 57: 697-715.

McDonald AJ, Augustine JR. 1993. Localization of GABA-like immunoreactivity in the monkey amygdala. Neuroscience 52: 281-294.

McGaugh JL. 2002. Memory consolidation and the amygdala: A systems perspective. Trends Neurosci 25: 456-461.

McKernan MG, Shinnick-Gallagher P. 1997. Fear conditioning induces a lasting potentiation of synaptic currents in vitro. Nature 390: 607-611.

Miserendino MJD, Sananes CB, Melia KR, Davis M. 1990. Blocking of acquisition but not expression of conditioned fear-potentiated startle by NMDA antagonists in the amygdala. Nature 345: 716-718.

Pape HC, Paré D. 2010. Plastic synaptic networks of the amygdala for the acquisition, expression, and extinction of conditioned fear. Physiol Rev 90: $419-463$.

Paré D. 2002. Mechanisms of Pavlovian fear conditioning: Has the engram been located? Trends Neurosci 25: 436-437.

Paré D. 2003. Role of the basolateral amygdala in memory consolidation. Prog Neurobiol 70: 409-420.

Power JM, Bocklisch C, Curby P, Sah P. 2011. Location and function of the slow afterhyperpolarization channels in the basolateral amygdala. $J$ Neurosci 31: 526-537.

Quirk GJ, Repa JC, LeDoux JE. 1995. Fear conditioning enhances short latency auditory responses of lateral amygdala neurons: Parallel recordings in the freely behaving rat. Neuron 15: 1029-1039.

Quirk GJ, Armorny JL, LeDoux JE. 1997. Fear conditioning enhances different temporal components of tone-evoked spike trains in auditory cortex and lateral amygdala. Neuron 19: 613-624.
Rainnie DG, Mania I, Mascagni F, McDonald AJ. 2006. Physiological and morphological characterization of parvalbumin-containing interneurons of the rat basolateral amygdala. J Comp Neurol 498: $142-161$.

Rea K, Lang Y, Finn DP. 2009. Alterations in extracellular levels of $\gamma$-aminobutyric acid in the rat basolateral amygdala and periaqueductal gray during conditioned fear, persistent pain and fear-conditioned analgesia. J Pain 10: 1088-1098.

Repa JC, Muller J, Apergis J, Desrochers TM, Zhou Y, LeDoux JE. 2001. Two different lateral amygdala cell populations contribute to the initiation and storage of memory. Nat Neurosci 4: 724-731.

Rodrigues SM, LeDoux JE, Sapolsky RM. 2009. The influence of stress hormones on fear circuitry. Аnnu Rev Neurosci 32: 289-313.

Romanski LM, LeDoux JE. 1993a. Information cascade from primary auditory cortex to the amygdala: Corticocortical and corticoamygdaloid projections of temporal cortex in the rat. Cereb Cortex 3: 515-532.

Romanski LM, LeDoux JE. 1993b. Organization of rodent auditory cortex: Anterograde transport of PHA-L from MGv to temporal neocortex. Cereb Cortex 3: 499-514.

Rumpel S, LeDoux J, Zador A, Malinow R. 2005. Postsynaptic receptor trafficking underlying a form of associative learning. Science 308: $83-88$.

Sah P, Faber ES, Lopez de Armentia M, Power J. 2003. The amygdaloid complex: Anatomy and physiology. Physiol Rev 83: 803-834.

Samson RD, Paré D. 2006. A spatially structured network of inhibitory and excitatory connections directs impulse traffic within the lateral amygdala. Neuroscience 141: $1599-1609$.

Shi CJ, Cassell MD. 1997. Cortical, thalamic, and amygdaloid projections of rat temporal cortex. J Comp Neurol 382: 153-175.

Shinonaga Y, Takada M, Mizuno N. 1994. Direct projections from the nonlaminated divisions of the medial geniculate nucleus to the temporal polar cortex and amygdala in the cat. J Comp Neurol 340: 405-426.

Shouval HZ, Castellani GC, Blais BS, Yeung LC, Cooper LN. 2002. Converging evidence for a simplified biophysical model of synaptic plasticity. Biol Cybern 87: 383-391.

Sosulina L, Meis S, Seifert G, Steinhauser C, Pape HC. 2006. Classification of projection neurons and interneurons in the rat lateral amygdala based upon cluster analysis. Mol Cell Neurosci 33: 57-67.

Tsvetkov E, Carlezon WA, Benes FM, Kandel ER, Bolshakov VY. 2002. Fear conditioning occludes LTP-induced presynaptic enhancement of synaptic transmission in the cortical pathway to the lateral amygdala. Neuron 34: 289-300.

Tsvetkov E, Shin RM, Bolshakov VY. 2004. Glutamate uptake determines pathway specificity of long-term potentiation in the neural circuitry of fear conditioning. Neuron 41: $139-151$.

Tully K, Bolshakov VY. 2001. Emotional enhancement of memory: How norepinephrine enables synaptic plasticity. Mol Brain 3: 15 .

Turner BH, Herkenham M. 1991. Thalamoamygdaloid projections in the rat: A test of the amygdala's role in sensory processing. J Comp Neurol 313: $295-325$.

Tuunanen J, Pitkänen A. 2000. Do seizures cause neuronal damage in rat amygdala kindling? Epilepsy Res 39: 171-176.

Varela J, Sen K, Gibson J, Fost J, Abbott L, Nelson S. 1997. A quantitative description of short-term plasticity at excitatory synapses in layer $2 / 3$ of rat primary visual cortex. J Neurosci 17: 7926-7940.

Wang SJ, Gean PW. 1999. Long-term depression of excitatory synaptic transmission in the rat amygdala. J Neurosci 19: 10656-10663.

Washburn MS, Moises H.C. 1992. Electrophysiological and morphological properties of rat basolateral amygdaloid neurons in vitro. J Neurosci 12: $4066-4079$.

Weinberger NM. 2011. The medial geniculate, not the amygdala, as the root of auditory fear conditioning. Hear Res 274: 61-74.

Weisskopf MG, Bauer EP, LeDoux JE. 1999. L-type voltage-gated calcium channels mediate NMDA-independent associate long-term potentiation at thalamic input synapses to the amygdala. J Neurosci 19: $10512-10519$.

Woodruff AR, Sah P. 2007. Networks of parvalbumin-positive interneurons in the basolateral amygdala. J Neurosci 27: 553-563.

Woodson W, Farb CR, Ledoux JE. 2000. Afferents from the auditory thalamus synapse on inhibitory interneurons in the lateral nucleus of the amygdala. Synapse 38: 124-137.

Received January 4, 2013; accepted in revised form May 21, 2013. 


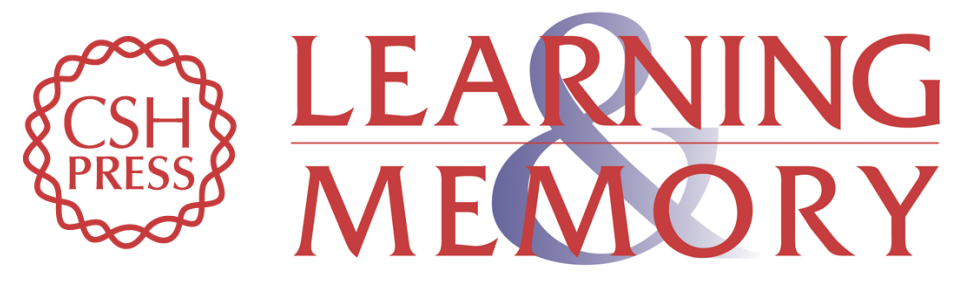

\section{Mechanisms contributing to the induction and storage of Pavlovian fear memories in the lateral amygdala}

Dongbeom Kim, Denis Paré and Satish S. Nair

Learn. Mem. 2013, 20:

Access the most recent version at doi:10.1101/Im.030262.113

\section{Supplemental http://learnmem.cshlp.org/content/suppl/2013/07/08/20.8.421.DC1 Material}

References This article cites 67 articles, 11 of which can be accessed free at: http://learnmem.cshlp.org/content/20/8/421.full.html\#ref-list-1

Creative This article is distributed exclusively by Cold Spring Harbor Laboratory Press for the Commons first 12 months after the full-issue publication date (see

License http://learnmem.cshlp.org/site/misc/terms.xhtml). After 12 months, it is available under a Creative Commons License (Attribution-NonCommercial 3.0 Unported), as described at http://creativecommons.org/licenses/by-nc/3.0/.

Email Alerting Receive free email alerts when new articles cite this article - sign up in the box at the Service top right corner of the article or click here. 